Виктория Коконова

ORCID: 0000-0003-0677-5037

Москва, Россия

\title{
ИНДЕЙЦЫ И ЧЕРНЫЕ РАБЫ В ПРОПОВЕДЯХ ПОРТУГАЛЬСКОГО МИССИОНЕРА АНТОНИУ ВИЭЙРЫ (1608-1697)
}

\author{
https://doi.org/10.34739/clit.2020.14.04
}

\author{
AMERICAN INDIANS AND BLACK SLAVES \\ IN THE SERMONS OF ANTONIO VIEIRA (1608-1697)
}

\begin{abstract}
The themes raised in the sermons of the Portuguese Jesuit Antonio Vieira were far ahead of their time. Already in the XVII century, the missionary questions the equality of Europeans, Africans and Indians before God, as well as the injustice of one race oppressing another. In his sermons, he asks his listeners to repent and reject slavery. He wants every colonist to become an apostle in his new homeland: to sow the faith of Christ and take care of the religious and moral education of his slaves. Uncovering the conflicts between the three ethnic groups, Vieira seeks to smooth out these contradictions, pointing out the ways of peaceful coexistence of the three cultures within the bosom of the same faith.

Keywords: sermon, Antonio Vieira, seventeenth-century Brazilian literature, seventeenth-century Portuguese literature, Brazilian slavery, Brazilian Indians, colonization, christianization
\end{abstract}

Антониу Виэйра - португальский миссионер-иезуит XVII в., чьи проповеди являются достоянием португальской и бразильской литературы. Он оставил после себя пятнадцать томов проповедей, многие из которых были изданы при его жизни.

Виейра приехал в Бразилию в 1614 г. в возрасте 6 лет. Он учился в Иезуитском Коллегиуме, а после учебы начал миссионерскую деятельность в «Обществе Иисуса». В Европу он возвращался всего 3 раза, что было связано с гонениями на него в колонии. Дело в том, что он был против рабства и выступал за создание индейских деревень под руководством отцов-иезуитов. Это не могло не возмущать богатых португальских колонистов, заинтересованных в бесплатной рабочей 
силе: «То, что Виейра был против рабства, превращало его во врага владельцев сахарных плантаций и купцов, и это могло стать причиной сговоров, в результате которых Инквизиция чуть не приговорила его к смерти как еретика»1.

Почти во всех проповедях, затрагивающих межэтнические отношения, Виейра критикует португальскую колониальную политику. Так, в проповеди на Первую пасхальную неделю Великого nоста, 1653 г. все рассуждения строятся вокруг евангельской истории об искушении Христа дьяволом и проповедуется идея об абсолютной ценности человеческой души.

Говоря о том, что дьявол предлагал Христу за его душу весь мир, Виейра сокрушается, что в его дни человеческая душа покупается и продается за бесценок, а многие люди обречены на вечное рабство. Чтобы подчеркнуть, что существующий в колонии экономической строй противен основам христианства, проповедник обращается к слушателям с такими словами:

Идите в Турцию, идите в ад, потому что не может быть в Турции такого турка, ни в аду такого демона, которые бы сказали, что свободный человек может быть невольником².

Даже ад признает, что рабство попирает универсальное право человека на свободу, а нравственное уродство рабовладения носит универсальный, надконфессиональный характер. По словам К. Берардинелли, «Виейра хочет преподать слушателям урок, (...): если жители Мараньяна не способны понять ценность своей души, то на это способен искуситель, потому что он такой же дух, как они, и знает, что душа дороже всего на свете»3. Именно через проповеди Виейра старается изменить отношение белого населения к рабовладению и привести их к раскаянию.

Проповедник указывает на нравственные последствия рабовладения, главного греха Бразилии. Все угнетатели неминуемо

\footnotetext{
${ }^{1}$ C. Silva, A visão do Padre Antônio Vieira sobre a escravidão, „Mafuá” 2011, № 16, https://mafua.ufsc.br/2011/a-visao-do-padre-antonio-vieira-sobre-a-escravidao/, [дата доступа: 10.11.2019].

2 ,ide à Turquia, ide ao inferno, porque não pode haver turco tão turco na Turquia, nem demônio tão endemoninhado no inferno, que diga que um homem livre pode ser cativo", A.Vieira, Sermão da Primeira Dominga de Quaresma, [in:] Sermoens do P. Antonio Vieira: segunda parte, Lisboa, 1682, http://purl.pt/292/5/l-5256-a_PDF/l-5256-a_PDF_24-CRoo75/l-5256-a_oooo_rosto-56_t24-C-Roo75.pdf, [дата доступа: 10.11.2019].

3 “(...) Vieira quer passar aos ouvintes uma lição (...): já que os homens do Maranhão não são capazes de perceber o valor de suas almas, tem-no o tentador, pois é espírito como elas e sabe que „vale uma alma mais que todo o mundo”, C. Berardinelli, Pretos, Índios e Judeus nos Sermões de Vieira, [in:] Estudos sobre Vieira, São Paulo 2011, p. 34.
} 
попадут в ад, и единственный способ этого избежать - покаяние и отказ от рабов, потому что экономическая выгода не может оправдать нравственного преступления колонистов:

Если король разрешит мне воровать, перестанет ли грабеж быть грехом? (...) Король может приказать, чтобы рабы стали свободными, но не в его праве приказать, чтобы свободные стали рабами 4 .

Другой способ повлиять на своих слушателей - обратить их души к духовному началу. Например, в Проповеди на Светлую Седмицу (1656), осуждается жажда наживы.

Проповедь написана на случай: в Мараньяне не нашли золотую руду, что Виейра считает милостью господней. По мнению проповедника, главное богатство Бразилии заключается не в полезных ископаемых, а в бессмертных душах, населяющих страну:

Все души одинаково ценны. Но (...) с каким пренебрежением их губят, когда алчно жаждут золота и серебра, когда ищут металлы с такой заботой и таким тщанием 5 .

Колонисты заботливо относятся к неживому металлу, а человека считают расходным материалом, чья ценность несравнимо ниже ценности золота и серебра. Однако в глазах Бога нет большей ценности, чем человеческая душа, потому что Христос заплатил за каждую из них своей кровью.

Еще один аспект проповедей Виейры затрагивает особенности христианизации Бразилии и сложности. Наиболее подробно об этом говорится в Проповеди о Святом Духе (1657). Проповедь была прочитана в День Пятидесятницы, когда Святой дух снизошел на апостолов, и они стали понимать иностранные языки, что облегчило их миссионерскую деятельность.

Современники Виейры не были удостоены этого чуда, поэтому им самим приходилось изучать языки племен, которые они хотели обратить в католичество. И если каждый апостол стал понимать какойто один язык, то бразильским миссионерам приходилось учить десятки языков:

\footnotetext{
4 "Se el-rei permitir que eu furte, deixará o furto de ser pecado? (...) El-rei poderá mandar que os cativos sejam livres; mas que os livres sejam cativos, não chega lá sua jurisdição”, ibidem. 5 “(...) todas [as almas] custaram o mesmo - mas pelo desamparo e desprezo com que se estão perdendo, quando o ouro e a prata se deseja com tanta ânsia, se procura com tanto cuidado e se busca com tanto empenho?", A. Vieira, Sermão de Primeira Oitava de Páscoa, http://www.dominiopublico.gov.br/download/texto/fsooooogpdf.pdf, [дата доступа: 12.11.2019].
} 
Тех, кто строил Вавилонскую башню, Господь наказал тем, что они стали говорить на разных языках, но не учить их. Тех, кто проповедует веру язычникам, наказывают любовью к Богу. И это наказание заключается не только в том, что они должны говорить на языке язычников, но в том, что они должны их учить (...) .

Сравнение с Вавилонским столпотворением неслучайно, так как на берегах Амазонки во времена Виейры жило около 150 племен, каждое из которых говорило на своем собственном языке. По словам проповедника, языки индейцев не показывали никаких признаков лингвистического родства, поэтому работа миссионеров была похожа на Сизифов труд: выучив один язык, приходилось с самых основ учить следующий.

Именно миссионеры составили первые грамматики и тезаурусы многих языков, существовавших на территории Бразилии XVII в. Составлять их было сложно, потому что все эти языки были бесписьменными, а их грамматика и фонетика сильно отличались от грамматики индоевропейских языков:

(...) среди этой темноты и какофонии нужно построить фундамент и открыть первые рудименты языка: определить существительное, глагол, число, падеж, время, наклонение, и такие наклонения, о которых никто не слышал и которые никто не мог представить (...)7.

Но не языковой барьер был главным препятствием на пути христианизации бразильских аборигенов. Большей проблемой была невозможность христианизировать эти племена. Зачастую они охотно слушали проповеди, но не становились христианами, продолжая соблюдать языческие ритуалы. Поэтому Виейра сокрушается о зыбкости и непрочности их веры:

(...) это вера, потому что они верят без сомнений и исповедают без отвращения то, чему их научили, но она кажется неверием, потому что

\footnotetext{
6 "Aos que edificavam a Torre de Babel condenou-os a justiça de Deus a falar diversas línguas, mas não a aprendê-las; aos que pregam a fé entre as gentilidades, condena-os o amor de Deus, não só a que falem as suas línguas (...)”, A. Vieira, Sermão do Espirito Santo, http://tupi.fflch.usp.br/sites/tupi.fflch.usp.br/files/SERM\%C3\%83O\%20DO\%20ESP\%C3\% 8DRITO\%2OSANTO.pdf, [дата доступа: 12.11.2019].

7 “(...) no meio daquela escuridade e dissonância haver de cavar os primeiros alicerces, e descobrir os primeiros rudimentos dela, distinguir o nome, o verbo, o advérbio, a proposição, o número, o caso, o tempo, o modo, e modos nunca vistos nem imaginados, como de homens enfim tão diferentes dos outros nas línguas, como nos costumes, não há dúvida que é empresa muito árdua a qualquer entendimento", ibidem.
} 
с той же легкостью, с которой они учатся, они забывают то, чему научились, и с той, же легкостью, с которой верят, перестают верить ${ }^{8}$.

Непостоянство индейцев миссионер сравнивает с изменчивостью мирта, который легко принимает любую форму, но так же легко ее теряет, возвращаясь к дикому состоянию. Развертывая эту метафору, Виейра призывает своих собратьев «(...) работать против природы ствола и прихоти корней, потому что только так можно придать этим растениям ненатуральную форму»9. Только постоянное пребывание среди индейцев, постоянная проповедь и собственный пример могут заставить коренное население отказаться от языческих суеверий.

Виейра добивался у португальского короля, чтобы индейцев освободили и отдали под управление иезуитов, потому что колонисты не уделяли достаточно внимания религиозному воспитанию своих рабов. После встречи проповедника с королем Жуаном IV в 1655 г. был принят закон, по которому колонисты не могли воевать против индейцев без одобрения короля. Кроме того, было утверждено создание индейских деревень под управлением иезуитов. Но в реальности ничего не было достигнуто, потому что король вскоре умер, а его преемник дон Педру II стал вести другую политику.

Но Виейра не теряет веры в то, что и индейцев можно обратить в христианство. Эту мысль он иллюстрирует, вновь обращаясь к природе. Он уподобляет их грубым камням, а работу проповедника работе скульптора, который с помощью резца высекает статую из каменной глыбы:

Так этот индеец, как вы говорите, камень? Тогда продолжайте над ним работать, потому что ничего не делается без работы и настойчивости подносите к нему резец один день и другой день, долбите раз и еще раз, и вы увидите, как из этого тусклого и бесформенного камня вы сделаете не просто человека, но христианина, а возможно и святого ${ }^{10}$.

8 “(...) é fé que parece incredulidade, e é incredulidade que parece fé; é fé, porque crêem sem dúvida e confessam sem repugnância tudo o que lhes ensinam, e parece incredulidade, porque, com a mesma facilidade com que aprenderam, desaprendem, e com a mesma facilidade, com que creram, descrêem", ibidem.

9 “(...) trabalhando sempre contra a natureza do tronco e humor das raízes, se pode conservar nestas plantas rudes a forma não natural, e compostura dos ramos”, ibidem.

10 "É uma pedra, como dizeis, esse índio rude? Pois, trabalhai e continuai com ele - que nada se faz sem trabalho e perseverança - aplicai o cinzel um dia e outro dia, dai uma martelada e outra martelada, e vós vereis como dessa pedra tosca e informe fazeis não só um homem, senão um cristão, e pode ser que um santo", ibidem. 
Хотя работа проповедника может показаться бессмысленной, Виейра считает, что отказываться от нее нельзя, потому что Господь наказал распространять веру среди всех тварей Божиих:

(...) если апостолы должны проповедовать всем тварям, то они должны проповедовать и животным? И стволам? И деревьям? Да, говорит Христос, всем тварям. И не потому, что апостолы должны были проповедовать камням, стволам и животным, но потому, что они должны были проповедовать среди всех варварских и нецивилизованных племен и народов, среди которых они могли найти людей неразумных и нечувствительных, как стволы, и твердолобых и глупых, как камни ${ }^{11}$.

Как видно, проповедник способен увидеть красоту человеческой души даже там, где обычный человек видит лишь грубость и дикость. Именно в этом заключается его высокое предназначение. Однако, подчеркивает Виейра, не только миссионеры должны быть апостолами христианской веры в Бразилии - все колонисты обязаны быть примером праведного христианина, не только мужчины, но и женщины:

(...) мужчины, проповедуя в полях, приводят души в церковь и выполняют работу апостолов. А женщины в своем доме, обучая доктрине рабов и рабынь, тоже выполняют работу апостолов ${ }^{12}$.

Таким образом, каждый португальский колонист становится проповедником и находится в ответе за спасение душ язычников. Смертельно грешит каждый, кто отказывает своим рабам в спасении души, пренебрегая распространением христианства. Поэтому на Страшном суде у рабов будет надежда на прощение, а у белых угнетателей - нет:

Раб оправдается своим господином, а как будет оправдывать себя господин? Раб может оправдать себя недостатком понимания, своим невежеством; а чем будет оправдывать себя господин? Своей жадностью? Своей безграничной слепотой? Недостатком милосердия?

${ }_{11}$ “(...) se os apóstolos hão de pregar a todas as criaturas, hão de pregar também aos brutos? Hão de pregar também aos troncos? Hão de pregar também às pedras? Também, diz Cristo: Omni creaturae; não porque houvessem os apóstolos de pregar às pedras, e aos troncos, e aos brutos, mas porque haviam de pregar a todas as nações e línguas bárbaras e incultas do mundo, entre as quais haviam de achar homens tão irracionais como os brutos, e tão insensíveis como os troncos, e tão duros e estúpidos como as pedras", ibidem.

12 “(...) eles na campanha trazendo almas para a Igreja, fazem ofício de apóstolos; e elas em suas casas, doutrinando seus escravos e escravas, fazem ofícios de apóstolas”, ibidem. 
Недостатком человечности? Недостатком христианского духа? Недостатком веры? 13

В проповеди Мария, мистическая роза (1633) рабство критикуется с точки зрения равенства всех перед Богом. Проповедника огорчает, что идея Бога о человеке получила в колониальном обществе искаженное воплощение:

Бог сотворил людей из одного вещества, чтобы все жили вместе, а все друг от друга отделяются; сотворил их равными, а они хотят отличаться друг от друга; Он сотворил их братьями, а они стыдятся своего родства ${ }^{14}$.

Хотя проповедь начинается с обвинения представителей всех рас, но в дальнейшем она становится своеобразной речью в защиту и прославление черных рабов. Это делается через сравнение с Девой Марией и Иисусом, что подчеркивает не только родство рабов с сакральными христианскими образами, но и их нравственное превосходство над колонизаторами.

Во-первых, сама Мария в день Благовещения называет себя рабой Господней воли. Кроме того, подчеркивает Виейра, Бог-Отец выбрал именно Марию, девушку из небогатой семьи для исполнения своего замысла, потому что она была богаче всех своими душевными качествами. И Виейра призывает последовать примеру Бога-Отца в суждении о ближних, потому что белый цвет лица не имеет никакой ценности, если у человека черная душа: «Уголь, покрытый снегом, не перестает быть углем, но становится еще чернее по сравнению с ним»15.

Черный и белый цвета используются для аллегорического изображения моральных качеств, подчеркивая контраст между белизной лица и нравственными качествами человека. И симпатия Виейры оказывается совсем не на стороне белых. Наоборот, именно черные рабы ближе и милее Христу, чем их белые хозяева. Все потому, что «из всего, что создал Бог, он взял себе лучшее, то есть природу человека, а из всего, что люди придумали на земле, он взял худшее, то

${ }_{13}$ "O escravo escusar-se-á com o seu senhor; mas o senhor, com quem se há de escusar? O escravo poder-se-á escusar com o seu pouco entendimento, com a sua ignorância; mas o senhor, com que se escusará? Com a sua muita cobiça? Com a sua muita cegueira? Com faltar à piedade? Com faltar à humanidade? Com faltar à cristandade? Com faltar à fé?”, ibidem.

14 "Fê-los Deus a todos de uma mesma massa, para que vivessem unidos, e eles se desunem; fê-los iguais, e eles se desigualam; fê-los irmãos, e eles se desprezam do parentesco", A. Vieira, Maria Rosa Mística, http://www.dominiopublico.gov.br/download/texto/bvoooo28.pdf, [дата доступа: 12.11.2019].

15 "O carvão coberto de neve, nem por isso deixa de ser carvão, antes, junto dela é mais negro", ibidem. 
есть положение раба»16. Как раб, Христос омывает ноги и умирает, как раб, на кресте. Кроме того, Иуда продает его как раба и за бесценок. Все эти сравнения нужны Виейре для того, чтобы призвать своих слушателей не только уважать в рабах людей, но и видеть в них божественное начало: «И если это самые большие унижения, ожидающие раба, найдется ли кто-то, если у него есть вера, кто осмелится презирать в своем рабе то, что он видит в своем Боге?»17.

По мнению Виейры, угнетенные вызывают у Бога и Девы Марии больше симпатий, чем богатые, которых развращает достаток. У белых нет никакого преимущества перед черными в глазах Бога, и Виейра формулирует очень смелую, хотя и закономерную мысль: «То, что белые доминируют над индейцами - это закон силы, а не разума или природы» ${ }^{18}$.

В Четырнадцатой проповеди (1633) проповедник продолжает защиту черных рабов через сакрализацию. Эта проповедь интересна тем, что Виейра прочитал ее рабам одной сахарной плантации. То есть перед ним стояла задача возвысить рабов в их собственных глазах, укрепить их веру и утешить их.

Прежде всего, рабы такие же сыновья Девы Марии, как и белые, потому что все христиане являются ее сыновьями по вере. Виейра утверждает, что главное утешение рабов заключается в спасении: хотя они и находятся вдали от родины и лишены свободы, они должны быть благодарны Богу за возможность спасения:

Если бы черные люди, которых вырвали из эфиопских лесов и отправили в Бразилию, знали, как они обязаны Богу и Богородице за то, что может показаться изгнанием, рабством, неволей и несчастьем, а на самом деле является чудом, и великим чудом. Скажите мне: ваши отцы, которые родились и живут во мраке язычества, и заканчивают жизнь без света веры и знания о Боге, куда они попадут после смерти?19

\footnotetext{
16 "De quanto Deus tinha criado na terra, tomou o melhor, que era a natureza humana, e de quanto os homens tinham inventado na mesma terra, tomou o pior, que era a condição de escravo", ibidem.

17 "E se estes são os maiores abatimentos a que pode chegar o estado da servidão, quem haverá, se tem fé, que se atreva a desprezar no seu escravo o que vê no seu Deus?”, ibidem.

18 "Entre os homens dominarem os brancos aos pretos é força, e não razão ou natureza", ibidem.

19 "Oh! se a gente preta, tirada das brenhas da sua Etiópia, e passada ao Brasil, conhecera bem quanto deve a Deus e a sua Santíssima Mãe por este que pode parecer desterro, cativeiro e desgraça, e não é senão milagre, e grande milagre? Dizei-me: vossos pais, que nasceram nas trevas da gentilidade, e nela vivem e acabam a vida sem lume da fé nem conhecimento de Deus, aonde vão depois da morte?”, A. Vieira, Sermão XIV, https://www.literaturabrasileira. ufsc.br/documentos/?action=download\&id=49751, [дата доступа: 12.11.2019].
} 
Миссионер восхищается стойкостью и терпением африканских невольников, описывая их положение следующими словами: «Нет ни работы, ни жизни в этом мире, которые бы больше походили на Крест и Страсти Христовы, чем ваш труд на сахарных плантациях» 20 . Но не только со страстями Христовыми схожа их работа. Дальше Виейра спрашивает: «(...) что в хаосе этого мира больше всего похоже на ад, чем любая из ваших сахарных плантаций (...)?»²1.

Виейра обещает, что за ад на земле рабы будут вознаграждены вечным блаженством, так как они уподобятся Христу не только в страстях, но и в Воскресении и Вознесении, потому что «за радостями этой жизни следуют печали, а за печалями, напротив, слава»22.

Таким образом, Антониу Виейра стремился в своих проповедях донести до слушателей евангельскую мысль о том, что «нет ни эллина, ни иудея ${ }^{23}$ », или, перенося эту идею на бразильскую землю, что нет ни белых, ни красных, ни черных, потому что все равны перед Богом.

Миссионер был известен своими либеральными, прогрессивными взглядами: он защищал иудеев, был против зверского обращения с рабами в Бразилии и даже призывал помещиков освободить своих индейских рабов. Его проповеди, где говорится о сосуществовании белого, индейского и черного населения, всегда вскрывают конфликтные отношения между тремя этникокультурными группами и стремятся сгладить эти конфликты.

\section{Литература}

Виэйра А., Избранные произведения, Москва 2007.

Besselaar, J., António Vieira: O homem, a obra, as ideias, Lisboa 1981.

Berardinelli C., Pretos, Índios e Judeus nos Sermões de Vieira, in: Estudos sobre Vieira, São Paulo 2011, p.25-45.

Borges, P., A Plenificação da História em Padre António Vieira, Lisboa 1995.

Fernandes, M., O padre Antonio Vieira e o método da pregação, "Revista Pistis \& Práxis: Teologia e Pastoral" 2010, №1, p. 211-230.

Margutti, P., O Padre Antônio Vieira e o pensamento filosófico brasileiro, "Síntese" 2008, №112, p.167-188.

Oliveira Santos, I., Padre Antônio Vieira e o projeto colonial: uma análise da IV Parte do Sermão da Sexagésima, "Revista de cultura teológica" 2015, №85, p.89-105.

\footnotetext{
20 "Não há trabalho nem gênero de vida no mundo mais parecido à Cruz e Paixão de Cristo que o vosso em um destes engenhos", ibidem.

21 "[...] que coisa há na confusão deste mundo mais semelhante ao inferno que qualquer destes vossos engenhos, e tanto mais quanto de maior fábrica?”, ibidem.

22 "Porque os gostos desta vida têm por conseqüência as penas, e as penas, pelo contrário, as glórias", ibidem.

23 Послание к Колоссянам апостола Павла.
} 
Paiva, J., Padre Antonio Vieira: 1608-1697: bibliografia, Lisboa 1999.

Pécora, A., A escravidão nos sermões do Padre Antonio Vieira, "Estudos Avançados" 2019, №33, p.153-170.

Pinto P., Alteridade e Humanismo em Vieira, "Brotéria: Cristianismo e cultura” 2013, №3, p. 251-270.

Saraiva, A., O discurso engenhoso: ensaios sobre Vieira, Lisboa 1996.

Silva C., A visão do Padre Antônio Vieira sobre a escravidão, "Mafuá", 2011, № 16, https://mafua.ufsc.br/2011/a-visao-do-padre-antonio-vieira-sobrea-escravidao/.

Vieira A., Sermões Escolhidos, v.I, São Paulo 1965.

Vieira A., Sermoens do P. Antonio Vieira: segunda parte, Lisboa 1682, http://purl.pt/292/5/l-5256-a_PDF/l-5256-a_PDF_24-C-Roo75/l5256-a_00oo_rosto-56_t24-C-Roo75.pdf.

Vieira A., Sermão do Espírito Santo, http://purl.pt/292/5/l-5256-a_PDF/l5256-a_PDF_24-C-Roo75/l-5256-a_OOOO_rosto-56_t24-C-Roo75.pdf.

Vieira A., Sermão de Primeira Oitava de Páscoa, http://www.dominiopublico. gov.br/download/texto/fsooooogpdf.pdf.

Vieira A., Maria Rosa Mística, http://www.dominiopublico.gov.br/ download/texto/bvoooo28.pdf.

Vieira A., Sermão XIV, https://www.literaturabrasileira.ufsc.br/documentos/ ?action=download\&id=49751.

\section{References}

Berardinelli C., Pretos, Índios e Judeus nos Sermões de Vieira, in: Estudos sobre Vieira, São Paulo 2011, p.25-45.

Besselaar, J., António Vieira: O homem, a obra, as ideias, Lisboa 1981.

Borges, P., A Plenificação da História em Padre António Vieira, Lisboa 1995.

Fernandes, M., O padre Antonio Vieira e o método da pregação, "Revista Pistis \& Práxis: Teologia e Pastoral” 2010, №1, p. 211-230.

Margutti, P., O Padre Antônio Vieira e o pensamento filosófico brasileiro, "Síntese" 2008, №112, p.167-188.

Oliveira Santos, I., Padre Antônio Vieira e o projeto colonial: uma análise da IV Parte do Sermão da Sexagésima, "Revista de cultura teológica" 2015, №85, p.89-105.

Paiva, J., Padre Antonio Vieira: 1608-1697: bibliografia, Lisboa 1999.

Pécora, A., A escravidão nos sermões do Padre Antonio Vieira, "Estudos Avançados" 2019, №33, p.153-170.

Pinto P., Alteridade e Humanismo em Vieira, "Brotéria: Cristianismo e cultura" 2013, №3, p. 251-270.

Saraiva, A., O discurso engenhoso: ensaios sobre Vieira, Lisboa 1996.

Silva C., A visão do Padre Antônio Vieira sobre a escravidão, "Mafuá", 2011, № 16, https://mafua.ufsc.br/2011/a-visao-do-padre-antonio-vieira-sobrea-escravidao/. 
Vieira A., Sermão do Espírito Santo, http://purl.pt/292/5/1-5256-a_PDF/15256-a_PDF_24-C-Roo75/l-5256-a_Oooo_rosto-56_t24-C-Roo75.pdf.

Vieira A., Sermoens do P. Antonio Vieira: segunda parte, Lisboa 1682, http://purl.pt/292/5/1-5256-a_PDF/1-5256-a_PDF_24-C-Roo75/l-5256 -a_00oo_rosto-56_t24-C-Roo75.pdf.

Vieira A., Maria Rosa Mística, http://www.dominiopublico.gov.br /download/texto/bvoooo28.pdf.

Vieira A., Sermão de Primeira Oitava de Páscoa, http://www.dominiopublico.gov.br/download/texto/fsooooogpdf.pdf.

Vieira A., Sermão XIV, https://www.literaturabrasileira.ufsc.br/documentos/ ?action $=$ download\&id $=49751$.

Vieira A., Sermões Escolhidos, v.I, São Paulo 1965.

Vièjra A., Izbrannye proizvedeniâ, Moskva, 2007. 